\title{
Application of fuzzy comprehensive evaluation to evaluate the effect of water flooding development
}

\author{
Ping Zhang ${ }^{1} \cdot$ Guoqing Feng ${ }^{1}$
}

Received: 16 July 2017 / Accepted: 26 November 2017 / Published online: 13 January 2018

(c) The Author(s) 2018. This article is an open access publication

\begin{abstract}
Fuzzy comprehensive evaluation (FCE) is a synthetic appraisement method based on fuzzy mathematics, and evaluation result is practical and reliable, therefore, which is widely used in petroleum, construction and many other fields. This paper applies it to the evaluation of water flooding effect of oilfield. This paper introduces the principle of FCE method and the evaluation steps. The method is applied to the evaluation of water flooding development effect, which is helpful to improve the analysis level of oil and gas field development. Compared with the traditional method, this proposed method can reflect the difference of the evaluation units. Meanwhile, the weight vector is gotten by entropy method and analytic hierarchy process (AHP), which making the evaluation results more convincing. Taking $\mathrm{W}$ oilfield as an example, the ten factors (e.g., reserves controlled degree of water flooding, reserves producing degree of water flooding, recovery percent of recoverable reserves, water cut, water storage rate, oil recovery rate of residual recoverable reserves, cumulative water injection, maintenance of formation pressure, comprehensive decline rate, water flooding recovery) were evaluated by proposed FCE method. Then the membership matrix is established, and the weight vector is calculated by the entropy method and the AHP. Finally, the evaluation results of the two methods are obtained by fuzzy transformation and are consistent with the actual water flooding effect. Thus, the FEC method can be used as method to accurately evaluate the effect of oil field water flooding.
\end{abstract}

Keywords Fuzzy comprehensive evaluation (FCE) · Water flooding development effect · Entropy method · Analytic hierarchy process (AHP)

\begin{tabular}{ll}
\multicolumn{2}{l}{ Abbreviations } \\
FCE & Fuzzy comprehensive evaluation \\
AHP & Analytic hierarchy process \\
List of symbols \\
$U \quad$ Evaluation index set \\
$V \quad$ Evaluation set \\
$R_{i} \quad$ Single factor evaluation vector \\
$R$ & Evaluation matrix \\
$\mu(x)$ & Ridge distribution function \\
$X$ & Weight vector \\
$P$ & Judgment matrix \\
$X_{k}$ & Feature vector \\
$\lambda_{k}$ & Maximum eigenvalue, $k=1,2, \ldots$ \\
$\otimes$ & Fuzzy operation \\
$Y$ & Comprehensive results of evaluation
\end{tabular}

Ping Zhang

1908679135@qq.com

1 Key Laboratory of Oil and Gas Reservoir Geology and Exploitations, Southwest Petroleum University, Chengdu 610500, China
$Q_{\mathrm{i}} \quad$ Cumulative water injection $\left(10^{4} \mathrm{t}\right)$

$Q_{\mathrm{w}} \quad$ Cumulative water production $\left(10^{4} \mathrm{t}\right)$

$Q_{\text {o }} \quad$ Cumulative oil production $\left(10^{4} \mathrm{t}\right)$

$C_{\mathrm{p}} \quad$ Water storage rate (f)

$Z \quad$ Injection production ratio (f)

$B_{\mathrm{o}} \quad$ Crude oil volume factor (f)

$\rho_{\mathrm{o}} \quad$ Crude oil density $\left(\mathrm{g} / \mathrm{cm}^{3}\right)$

$S_{\mathrm{p}} \quad$ Water flooding index (f)

$R_{m} \quad$ Ultimate oil recovery (\%)

$r \quad$ Recovery percent (\%)

\section{Introduction}

FCE is a comprehensive evaluation method based on fuzzy mathematics. Quantitative evaluation is converted to qualitative evaluation by FCE based on the membership degree theory of fuzzy mathematics. It evaluates the change of membership degree and judges things from multiple indexes. On the one hand, it takes into account the level of the object, making the evaluation criteria and the impact of fuzzy factors can be reflected. On the other 
hand, it can give full play to people's experience, making the evaluation results more objective and real. FCE can be combined with qualitative and quantitative factors, which expands the amount of information and evaluates credibility of conclusion. In addition, it also can be better to solve the fuzzy and difficult to quantify the problem. So it is suitable for solving a variety of non-deterministic problems. The following introduces the development of fuzzy comprehensive evaluation method.

To express the uncertainty of things, Zadeh (1965) put forward the concept of fuzzy set theory, which marks the birth of the new discipline of fuzzy mathematics. Subsequently, Zadeh (1974) proposed the concept of linguistic variables and explored the meaning of it. The AHP was developed by Saaty (1977) and originally applied to the marketing sector. Dolan (1989) firstly applied this method to health economics research. The concept of fuzzy language is one of the most important developments in fuzzy set theory. The concept of multisets and fuzzy multisets was proposed by Miyamoto (2000). Zheng and Tian (2009) used entropy method and analytic hierarchy process to obtain weight, which makes the result more reliable. Torra (2010) firstly defined a hesitant fuzzy set. Hesitant fuzzy set is different from classical fuzzy set, and can be composed of a plurality of real numbers.

Fuzzy comprehensive evaluation method was proposed to predict the remaining oil distribution by Hou et al. (2011). It is seen that this method can predict whether there is remaining oil in the pore space or not with satisfactory accuracy, which is above $75 \%$. Zheng et al. (2011) established the reservoir evaluation index system by fuzzy comprehensive evaluation method based on water flooding reservoir characteristics and influential factors.

You et al. (2014) analyzed the comprehensive classification reservoir's producing conditions during the ultra-high water cut developing phase based on multilevel fuzzy comprehensive evaluation mathematics method. Moreover, they established a quantitative evaluation method from geological and developmental factors, which solved the problem of analyzing remaining oil in different kinds of reservoirs and pointed out the quantitative characterization of remaining oil in the ultra-high water cut oilfield.

Wen et al. (2017) developed the index system evaluating water flooding development effect of oilfield at ultra-high water cut stage based on Pearson correlation analysis and gray clustering-rough set quantitative evaluation index.

Above all, FCE method is widely used in medical, construction, environmental quality supervision, traffic management, image processing, market forecast and many other fields. Recently, this method is more and more applied to the oil field, which is used to evaluate the distribution of permeability. After research, it is applied to the evaluation of water flooding effect in this paper.
The evaluation of oilfield development effect runs through the whole process of oil field development and provides the basis for the development of technology policy. In other word, it can offer a reference for formulating clear potential direction and reasonable regulation and control measures in oilfield development. Therefore, it is particularly important to evaluate the effect of water flooding in oil field. In this paper, the FCE method is used to evaluate the effect of water flooding in oilfield.

\section{The principle of fuzzy comprehensive evaluation}

FCE method is the application of fuzzy transformation and maximum degree of membership principle. Firstly, the fuzzy set is used to represent the various factors related to the evaluation object. Next, it is used to calculate the evaluation matrix and weight of evaluation factors. Finally, fuzzy linear transformation is used to get the evaluation results of fuzzy sets. This method can be applicable for solving the problem of multi factor complexity and uncertainty.

\section{Evaluation index set and evaluation set}

Given two finite fields, in which $U$ represents a comprehensive evaluation index set, $V$ represents the evaluation set (Sun 2008).

$U=\left(u_{1}, u_{2}, \ldots, u_{n}\right)$

where $u_{i}(i=1,2, \ldots, n)$ represents each evaluation factor, $\mathrm{n}$ is an integer.

$V=\left(v_{1}, v_{2}, \ldots, v_{m}\right)$

where $v_{i}(i=1,2, \ldots, m)$ represents each evaluation comment, $m$ is an integer.

\section{Evaluation matrix}

The membership matrix is the degree of membership of an index to a comment. If the membership of the $i$ th index $U_{i}$ and the $j$ th comments $V_{j}$ is symbol as $r_{i j}$, then the $i$ th index of the membership is expressed as:

$R_{i}=\left(r_{i 1}, r_{i 2}, r_{i 3}, \ldots, r_{i j}, \ldots r_{i m}\right)$

$R_{i}$ is a single factor evaluation vector, in which the value of $r_{i 1}, r_{i 2}, \ldots, r_{i m}$ is determined by the classical ridge distribution function Eq. 4. Then the membership value is normalized to get the single factor evaluation vector. And all the single factor matrices constitute the evaluation matrix $R$ (Chen and Zhang 2001). 
$\mu(x)= \begin{cases}0 & x \leq a \\ \frac{1}{2}+\frac{1}{2} \sin \frac{\pi}{b-a}\left(x-\frac{b+a}{2}\right) & a<x<b \\ 1 & b \leq x \leq c \\ \frac{1}{2}-\frac{1}{2} \sin \frac{\pi}{d-c}\left(x-\frac{d+c}{2}\right) & c<x<d \\ 0 & x \geq d\end{cases}$

$R=\left[\begin{array}{c}R_{1} \\ R_{2} \\ \ldots \\ R_{m}\end{array}\right]=\left[\begin{array}{cccc}r_{11} & r_{12} & \ldots & r_{1 \mathrm{~m}} \\ r_{21} & r_{22} & \ldots & r_{2 m} \\ \ldots & \ldots & \ldots & \ldots \\ r_{n 1} & r_{n 2} & \ldots & r_{n m}\end{array}\right]$

\section{Weight matrix}

Each evaluation factor $u_{i}$ determines $x_{i}$, indicating the importance of the evaluation results. A set $X$ called a weight set or a weight vector is composed of $x_{i}$.

$X=\left(x_{1}, x_{2}, \ldots, x_{n}\right) \quad 0 \leq x_{i} \leq 1$

There are many methods to calculate the weight, for example, entropy method and analytic hierarchy process (AHP).

\section{(1) Entropy method}

Entropy is a measure way to the degree of unordered system. It can be used to measure the amount of available information through known data and determine the weights in the fuzzy evaluation. That is to say, the weight of each index is determined by the difference degree of each index value.

The detailed steps to calculate the weight of entropy method are as follows (Zheng and Tian 2009):

(a) Original data matrix normalization. The original data matrix of $m$ evaluation index and $n$ evaluation comment is $R=\left(r_{i j}\right)_{m \times n}$, and the normalized matrix is $A=\left(a_{i j}\right)_{m \times n}$. In terms of the index of excellence, the normalized formula is:

$a_{i j}=\frac{r_{i j}-\min _{j}\left\{r_{i j}\right\}}{\max _{j}\left\{r_{i j}\right\}-\min _{j}\left\{r_{i j}\right\}}$

And for the small ones, the normalized formula is:

$$
a_{i j}=\frac{\max _{j}\left\{r_{i j}\right\}-r_{i j}}{\max _{j}\left\{r_{i j}\right\}-\min _{j}\left\{r_{i j}\right\}}
$$

b. Defined entropy. In the assessment of $m$ indicators and $n$ evaluation comment, the entropy of the $i$ th index is:

$h_{i}=-k \sum_{j=1}^{n} f_{i j} \ln f_{i j}$

where $f_{i j}=a_{i j} / \sum_{j=1}^{n} r_{i j}$

$k=1 / \ln n$

c. Defined entropy weight. After the entropy of the $i$ th index is defined, the entropy weight of the $i$ th index can be obtained:

$$
x_{i}=\frac{1-h_{i}}{m-\sum_{i=1}^{m} h_{i}} \quad\left(0 \leq x_{i} \leq 1, \sum_{i=1}^{m} x_{i}=1\right)
$$

(2) Analytic hierarchy process (AHP)

AHP is a simple and convenient method to quantitative analysis of non-quantitative events. It is in accordance with the decomposition, comparison, comprehensive way of thinking through regarding the research object as a decision-making system and has become an important tool to the system analysis. According to the relationship between
Table 1 Nine-grade intensity scale

\begin{tabular}{lllr}
\hline Definition & Explanation & $P_{i j}$ & $P_{j i}$ \\
\hline Equal importance & Two elements contribute equally to the objective & 1 & 1 \\
Moderate importance & Experience and judgment slightly favor one element over another & 3 & $1 / 3$ \\
Strong importance & Experience and judgment strongly favor one element over another & 5 & $1 / 5$ \\
Very strong importance & One element is favored very strongly over another, its dominance is & 7 & $1 / 7$ \\
& $\quad$ demonstrated in practice & & \\
Extreme importance & The evidence favoring one element over another is of the highest & 9 & $1 / 9$ \\
& possible order of affirmation &
\end{tabular}

Intensities of 2, 4, 6 and 8 can be used to express intermediate values. Intensities 1.1, 1.2, 1.3, etc. Can be used for elements that are very close in importance 
the components and membership, the multilevel structure is built by AHP. Based on the hierarchical structure model, we can obtain the judgment matrix. The maximum eigenvalue and the eigenvector of the judgment matrix $X$ are calculated by using the power method (Wen et al. 2017; Gerbacia and Hanaa 2001).

Firstly, the factor set $U=\left(u_{1}, u_{2}, \ldots, u_{n}\right)$ is determined, and then the judgment matrix $P=\left[P_{i j}\right]_{m \times n}$ is constructed by the following method, which $P_{i j}$ reflects the relationship between the two factors. And its values are shown in Table 1 (Ahmad et al. 2011).

After determining the judgment matrix $P$, the maximum eigenvalue and its corresponding feature vector are calculated, which is the order of importance of each evaluation factor. It also calls the weight coefficient of each evaluation factor. Using the power method calculates the largest eigenvalue of the judgment matrix $P$ and the corresponding eigenvector.

Initial vector $Z_{0}=(0,0, \ldots 0)$, then the power method iteration format (Chen and Zhang 2001):

$\left\{\begin{array}{l}X_{0}=Z_{0} \\ Z_{k}=P X_{(k-1)} \\ \lambda_{k}=\operatorname{Max}\left(Z_{k}\right) \\ X_{k}=Z_{k} / \lambda_{k}\end{array}\right.$

Take $x_{i}$ as the evaluation coefficient of the importance degree of the factor $U_{i}$, it can be normalized so that $\sum_{i=1}^{n} x_{i}=1$

\section{Fuzzy transformation}

The fuzzy transformation (Chen and Zhang 2001) is:

$Y=X \otimes R$

In fact, fuzzy transformation $Y$ is the synthesis of weight vector $X$ and fuzzy evaluation matrix $R$. In practical applications, it is generally done as follows:

$y_{i}=\sum_{i=1}^{m} x_{i} r_{i j}$

In the fuzzy transformation, $X$ is a fuzzy subset of $U$ and evaluation result of $Y$ is a fuzzy subset of $V$, which is the basic principle of comprehensive evaluation. Generally, $Y$ is a comprehensive evaluation of the results. In
$Y=\left(y_{1}, y_{2}, \ldots, y_{m}\right), y_{i}$ is the membership degree of the evaluation factors corresponding to the $i$ th fuzzy comment. According to the principle of maximum membership degree, the evaluation result is:

$y_{i}=\operatorname{Max}\left(y_{1}, y_{2}, \ldots, y_{m}\right) \quad 1 \leq i \leq m$

\section{Evaluation method and procedures}

Using the FCE method, the main steps of the comprehensive evaluation for the water flooding development effect of water flooding reservoir are shown in Fig. 1.

The model mainly includes three factors: factor set, evaluation set and weight set, namely. Firstly, the factor set is a set of indicators that affect the evaluation results of water flooding development, denoted as $U=\left(u_{1}, u_{2}, \ldots, u_{m}\right)$. In order to make the evaluation result simple and clear, using 5 levels of evaluation set, that is (excellent, good, general, poor, very poor), denoted as $v=\left(v_{1}, v_{2}, \ldots, v_{m}\right)$. Secondly, the evaluation set of the $i$ th factor $P=\left[P_{i j}\right]_{m \times n}$ is called the single factor evaluation vector or membership degree, denoted as $R_{i}=\left(r_{1}, r_{2}, r_{3}, r_{4}, r_{5}\right), \mathrm{n}$ factors of the single factor evaluation vector combination to form a matrix, called the evaluation matrix $R$. Finally, the evaluation results can be obtained by fuzzy transformation of judgment matrix $R$ and weight vector $X$, which is calculated by entropy method or AHP.

\section{Influence factor}

Water cut is an important index to evaluate the effect of oil field development, which not only affects the stability of oil field, but also directly affects the final recovery rate. The water storage rate, water flooding index and the recovery degree are the important indexes which reflect the development effect of the water injection field. It is directly related to the water injection rate and the total water cut.

\section{Water storage rate}

The water storage rate is the difference between water injection and water production in the development field of water injection, which is mainly characterized by the level of the utilization rate of water injection. The higher the value of the water storage rate, the higher the degree of utilization of the injected water, the better the development effect. According to
Fig. 1 Block diagram of single level fuzzy comprehensive evaluation

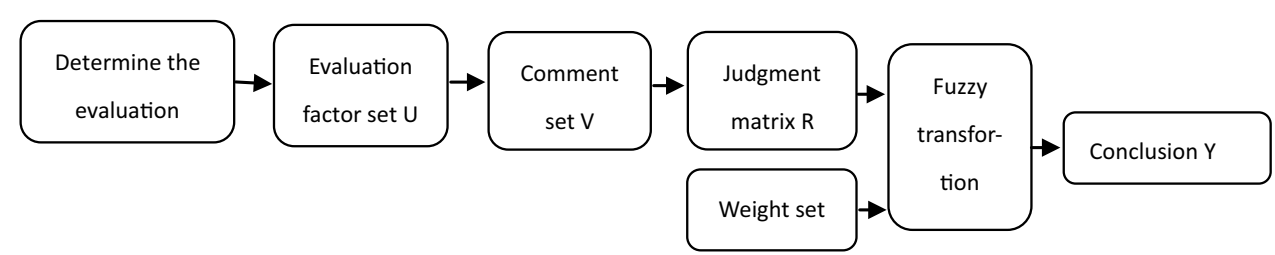


the definition of the water storage rate, the calculation formula

(Ma and Zhang 2016) for the water storage rate is:

$C_{\mathrm{p}}=\left[\left(Q_{\mathrm{i}}-Q_{\mathrm{w}}\right) / Q_{\mathrm{i}}\right] \times 100 \%$

And the expression of injection production ratio is:

$Z=Q_{\mathrm{i}} /\left(Q_{\mathrm{w}}+Q_{\mathrm{o}} \times \frac{B_{\mathrm{o}}}{\rho_{\mathrm{o}}}\right)$

Then:

$C_{\mathrm{p}}=1-1 /\left[Z\left(1+\frac{Q_{\mathrm{o}}}{Q_{\mathrm{w}}} \times \frac{B_{\mathrm{o}}}{\rho_{\mathrm{o}}}\right)\right]$

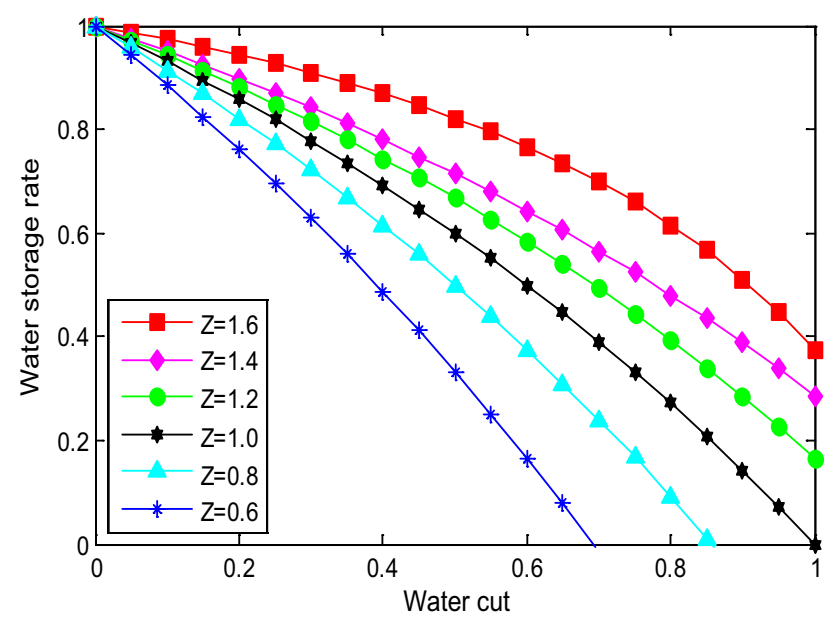

Fig. 2 The relationship curve of water storage rate and water cut
Due to water cut is:

$f_{\mathrm{w}}=\frac{Q_{\mathrm{w}}}{Q_{\mathrm{w}}+Q_{\mathrm{o}}}$

Then:

$C_{\mathrm{p}}=1-1 /\left[Z\left(1+\frac{1-f_{\mathrm{w}}}{f_{\mathrm{w}}} \times \frac{B_{\mathrm{o}}}{\rho_{\mathrm{o}}}\right)\right]$

From the above formula, the relationship between the water storage rate and the water cut is plotted as shown in Fig. 2.

\section{Water flooding index}

Water flooding index is defined as the amount of water stored in the ground for each ton of oil produced. The greater the water drive index, the greater the amount of water needed. According to the definition, the formula (Ma and Zhang 2016) is:

$S_{\mathrm{p}}=\left(Q_{\mathrm{i}}-Q_{\mathrm{w}}\right) /\left(\frac{B_{\mathrm{o}}}{\rho_{\mathrm{o}}} \times Q_{\mathrm{o}}\right)$

Expression of injection production ratio can be obtained:

$S_{\mathrm{p}}=Z+(Z-1)\left(\frac{\rho_{\mathrm{o}}}{B_{\mathrm{o}}} \times \frac{Q_{\mathrm{w}}}{Q_{\mathrm{o}}}\right)$

By water cut:

$$
S_{\mathrm{p}}=Z+(Z-1)\left(\frac{\rho_{\mathrm{o}}}{B_{\mathrm{o}}} \times \frac{f_{\mathrm{w}}}{1-f_{\mathrm{w}}}\right)
$$

Fig. 3 The relationship curve of water flooding index and water cut

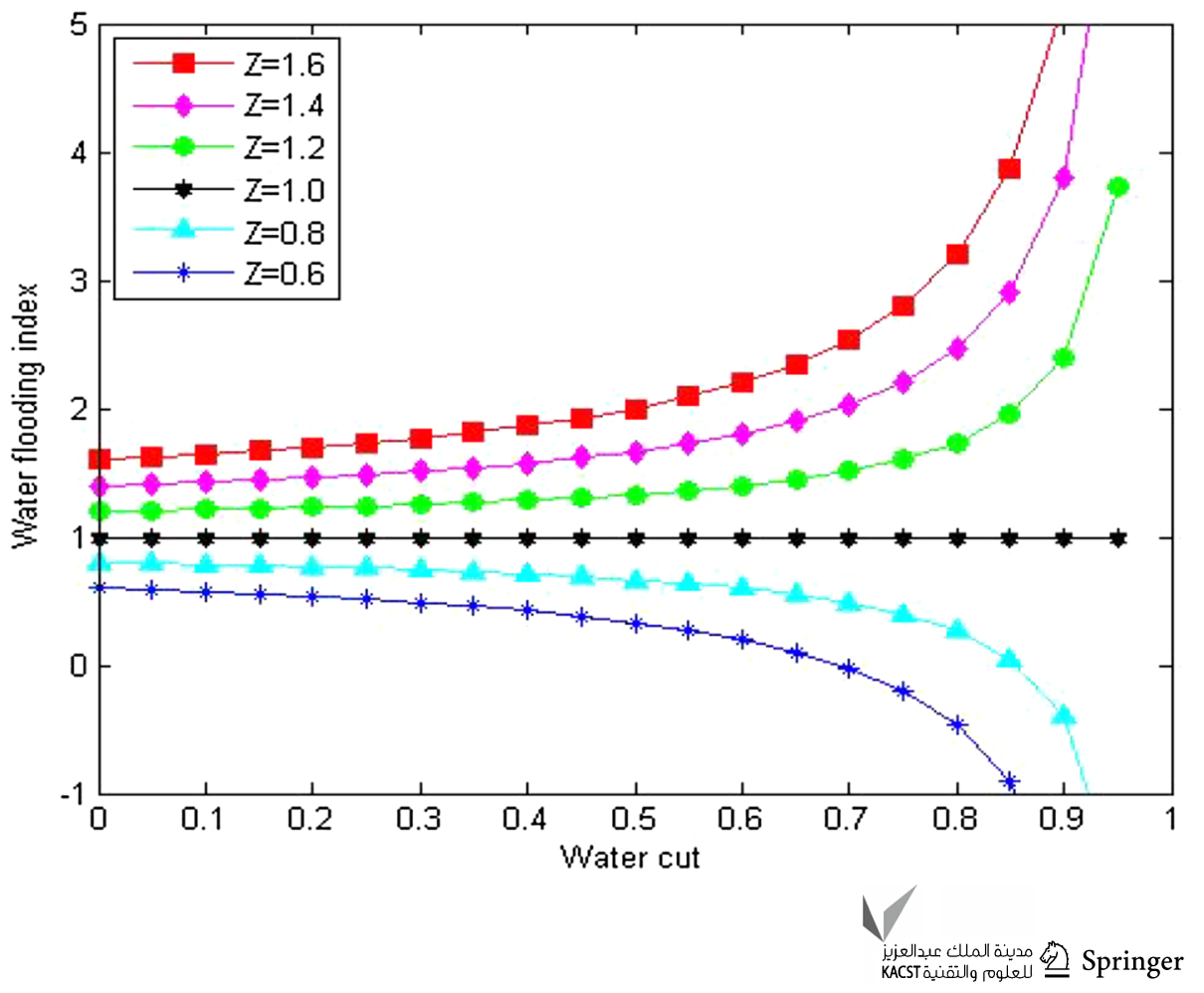


According to the above formula, the relationship between water flooding index and water cut is plotted based on different $Z$ values as shown in Fig. 3.

\section{Recovery degree}

The recovery degree is the percentage ratio of the cumulative oil production and using geological reserves, which reflects the recovery of the oil field reserves. Using the semiempirical formula derived from the Tong (1978) to determine the relationship between water cut and recovery degree in water injection development oilfield (Liang and Liu 2016):

$\lg \frac{f_{\mathrm{w}}}{1-f_{\mathrm{w}}}=7.5\left(r-R_{m}\right)+1.69$

According to the above formula, the relationship between recovery degree and water cut is plotted based on the different values of the water storage rate, as shown in Fig. 4.

There are many indexes evaluating the effect of water flooding development at present. In the index system of these factors, each index of the complex relationship and some indicators on development effect cannot give accurate evaluation. So the FCE method can be used to solve fuzzy, difficult to quantify and uncertainty problems, and the evaluation factors are more comprehensive and the evaluation results are more reliable.

\section{Case study}

W oilfield is lithological reservoirs with layered structure, has good reservoir properties but serious heterogeneity. Since it was developed in December 1977, it has experienced the adjustment of the layer system including first infilling and second infilling, local area well network encryption and improvement, well net comprehensive adjustment and other major adjustments. At present, it has entered a special high water cut period.

\section{Evaluation index}

Different development stages of oil field development indicators are not the same, different reservoir development stages need to establish the corresponding development evaluation system. Taking $\mathrm{W}$ oilfield as an example, this paper selects the representative and the most important indicators to evaluate water flooding development effect. The comprehensive evaluation index system of water injection reservoir is composed of three parts, which are injection production well network condition index, water injection condition index and development condition index.

According to the actual situation of the oil field, a set of comprehensive evaluation index system was established. Ten representative indexes were selected in this paper, the evaluation indexes and parameters of $\mathrm{W}$ oil field are shown in Table 2. These indicators constitute a set of factors $U=\left\{u_{1}, u_{2}, \ldots, u_{10}\right\}=\{$ Reserves controlled degree of
Fig. 4 The relationship curve of recovery degree and water cut

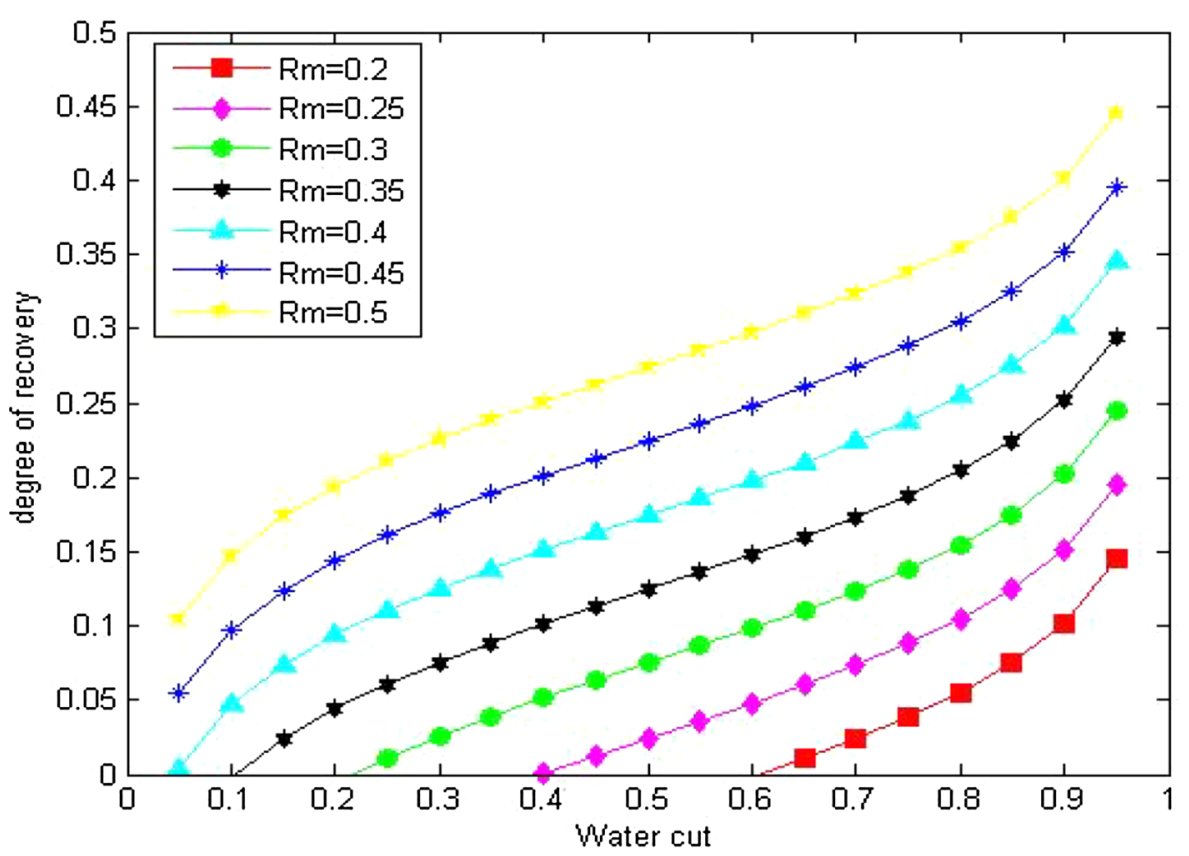


Table 2 Evaluation indexes and parameters of water flooding in $\mathrm{W}$ Oilfield

\begin{tabular}{llc}
\hline Number & Evaluation index & Value (\%) \\
\hline 1 & Reserves controlled degree of water flooding & 94.2 \\
2 & Reserves producing degree of water flooding & 59.99 \\
3 & Recovery percent of recoverable reserves & 77.01 \\
4 & Water cut & 94.93 \\
5 & water storage rate & 4.75 \\
6 & Oil recovery rate of residual recoverable & 4.39 \\
7 & reserves & $1.93 \mathrm{PV}$ \\
8 & Cumulative water injection & 86.69 \\
9 & Maintenance of formation pressure & $7.21 \mathrm{a}^{-1}$ \\
10 & comprehensive decline rate & 46.71 \\
\hline
\end{tabular}

water flooding, reserves producing degree of water flooding, recovery percent of recoverable reserves, water cut, water storage rate, oil recovery rate of residual recoverable reserves, cumulative water injection, maintenance of formation pressure, comprehensive decline rate, water flooding recovery\} (Wen et al. 2017).

On the basis of the actual geological characteristics and developed characteristics of the reservoir, comprehensive evaluation of evaluation index classification standard was proposed. This paper adopts the 5 grade evaluation criteria, namely the fuzzy comment set is $V=\left\{v_{1}, v_{2}, v_{3}, v_{4}, v_{5}\right\}=$ \{Excellent, Good, General, Poor, Very poor

In the light of Oilfield development level classification industry standard issued by Chinese Oil and Natural Gas Corp and related references, the range of evaluation criteria for development effects of each index is obtained in W oilfield. Reservoir level classification criteria and evaluation factors are shown in Table 3.

From Tables 2 and 3, the effect of water flooding is evaluated only by single factor and evaluation result is shown in Table 4. Obviously, the evaluation results of different factors are inconsistent, so it is not accurate enough using the single index to judge the water flooding effect of the oilfield. Thus, it is necessary to make a comprehensive evaluation of multiple factors.

\section{Evaluation matrix}

Single factor evaluation results of each index shown in Table 5 are calculated by Eq. 4 ; thus, the evaluation matrix $R$ is obtained. This method can minimize the impact of
Table $3 \mathrm{~W}$ oilfield water flooding index evaluation standard
Table 4 Evaluation result of single index water flooding effect in W Oilfield

\begin{tabular}{llcccc}
\hline Evaluation index & Excellent & Good & General & Poor & Very poor \\
\hline Reserves controlled degree of water flooding (\%) & $>85$ & $80-85$ & $75-80$ & $70-75<70$ \\
Reserves producing degree of water flooding (\%) & $>80$ & $75-80$ & $70-75$ & $65-70<65$ \\
Recovery percent of recoverable reserves (\%) & $>80$ & $75-80$ & $70-75$ & $65-70<65$ \\
Water cut (\%) & $<80$ & $80-85$ & $85-90$ & $90-95>95$ \\
Water storage rate (\%) & $>30$ & $20-30$ & $10-20$ & $5-10<5$ \\
Oil recovery rate of residual recoverable reserves (\%) & $>7$ & $6-7$ & $5-6$ & $4-5$ & $<4$ \\
Cumulative water injection (PV) & $<1.5$ & $1.5-2$ & $2-2.5$ & $2.5-3$ & $>3$ \\
Maintenance of formation pressure (\%) & $>100$ & $95-100$ & $90-95$ & $85-90$ & $<85$ \\
Comprehensive decline rate (a $\left.{ }^{-1}\right)$ & $\leq 6$ & $6-6.5$ & $6.5-7.5$ & $7.5-8$ & $>8$ \\
Water flooding recovery $(\%)$ & $>35$ & $30-35$ & $25-30$ & $20-25<20$ \\
\hline
\end{tabular}

\begin{tabular}{llll}
\hline Number & Evaluation index & Value & Evaluation result \\
\hline 1 & Reserves controlled degree of water flooding & $94.2 \%$ & Excellent \\
2 & Reserves producing degree of water flooding & $59.99 \%$ & Very poor \\
3 & Recovery percent of recoverable reserves & $77.01 \%$ & Good \\
4 & Water cut & $94.93 \%$ & Poor \\
5 & Water storage rate & $4.75 \%$ & Very poor \\
6 & Oil recovery rate of residual recoverable reserves & $4.39 \%$ & Poor \\
7 & Cumulative water injection & $1.93 \mathrm{PV}$ & Good \\
8 & Maintenance of formation pressure & $86.69 \%$ & Poor \\
9 & Comprehensive decline rate & $7.21 \% \mathrm{a}^{-1}$ & General \\
10 & Water flooding recovery & $46.71 \%$ & Excellent \\
\hline
\end{tabular}


Table 5 Distribution table of membership degree of evaluation index

\begin{tabular}{llllll}
\hline Evaluation index & Excellent & Good & General & Poor & Very poor \\
\hline Reserves controlled degree of water flooding (\%) & 0.724 & 0.239 & 0.037 & 0 & 0 \\
Reserves producing degree of water flooding (\%) & 0.052 & 0.172 & 0.224 & 0.263 & 0.288 \\
Recovery percent of recoverable reserves (\%) & 0.123 & 0.288 & 0.274 & 0.234 & 0.080 \\
Water cut (\%) & 0 & 0 & 0.103 & 0.601 & 0.296 \\
Water storage rate (\%) & 0 & 0 & 0.074 & 0.401 & 0.525 \\
Oil recovery rate of residual recoverable reserves (\%) & 0.074 & 0.226 & 0.273 & 0.294 & 0.133 \\
Cumulative water injection (PV) & 0.108 & 0.294 & 0.283 & 0.237 & 0.078 \\
Maintenance of formation pressure (\%) & 0.109 & 0.250 & 0.256 & 0.258 & 0.126 \\
Comprehensive decline rate (a $\left.{ }^{-1}\right)$ & 0.105 & 0.261 & 0.261 & 0.258 & 0.115 \\
Water flooding recovery (\%) & 0.429 & 0.276 & 0.182 & 0.094 & 0.019 \\
\hline
\end{tabular}

human subjective factors, making evaluation results more scientific and reasonable.

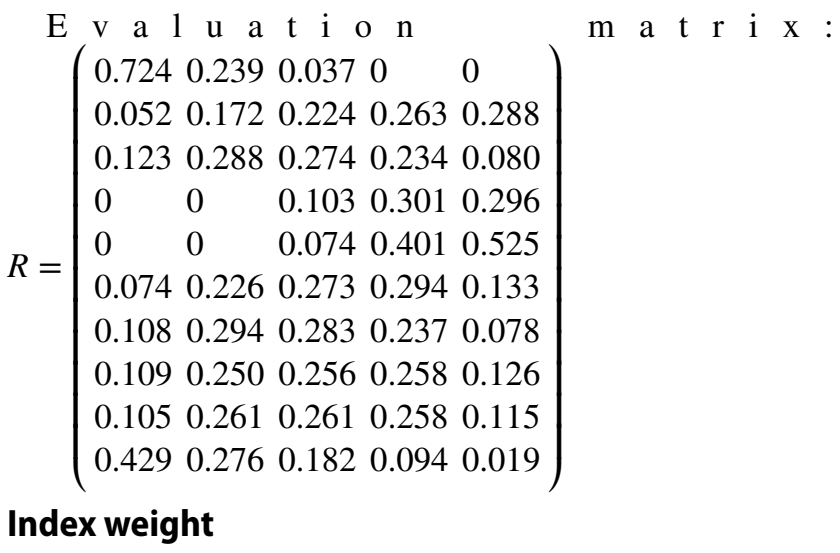

\section{(1) Entropy method}

Via Eqs. 7-10, using MATLAB programming calculate the weights of the indicators. The weight of the vector $X$ :

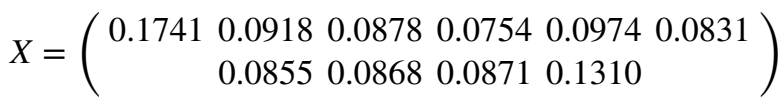

(2) Analytic hierarchy process (AHP)

We obtain the judgment matrix $P$ by water flooding index evaluation standard shown in Table 1 and calculate the maximum eigenvalue and its corresponding eigenvector by Eq. 11. The feature vector is each evaluation factor weight vector $X$; the calculation result is:

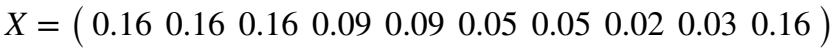

\section{Fuzzy Evaluation Results and Analysis}

The weight vectors calculated by the entropy method and AHP are added to Eqs. 12 and 13, which is to get the final result of the FCE. They are $(0.229,0.188,0.184,0.210$,
$0.190)$ and $(0.235,0.2030 .178,0.230,0.155)$, respectively. Based on the principle of the maximum membership degree, the results of the two methods are identical. We can conclude that the water flooding development effect is "excellent."

Combined with the single factor evaluation result of each index and the actual production characteristics of the oil reservoir, we can draw the conclusion that it should take a series of measures to adjust and improve the water flooding control degree, producing degree of water flooding and swept volume of water flooding, and further increase the recovery of water flooding in the $\mathrm{W}$ oilfield development process. As the plane heterogeneity and vertical heterogeneity lead to water cut rising fast and low water injection efficiency. Therefore, in the following mining, we should further improve water flooding reserves producing degree of the non-main oil layers, updip pinchout site of the main layers and subdivision out of thin and poor layers. Furthermore, we should further optimize the injection production system and promote the utilization rate of water injection in extra high water cut stage to improve the effect of water flooding development.

\section{Conclusions}

(1) The relationship between water storage rate, water drive index, extraction degree and water cut was calculated by the newly proposed formula, and the relationship curves were plotted, which has a guiding significance for the water drive adjustment of oil field.

(2) The fuzzy comprehensive evaluation method is used to evaluate the development of oil field and has a strong theoretical foundation. It can calculate many uncertain or only qualitative evaluation factors through fuzzy transformation and obtain the quantitative evaluation results, which are objective, reasonable, accurate and reliable. 
(3) Comparing the entropy method and the analytic hierarchy process, although the weight vector is not equal, the final evaluation result is consistent. The evaluation result is "excellent." According to the evaluation result, the main problems and adjustment suggestions of oil field development are pointed out. It indicates the direction of oilfield development and adjustment.

Open Access This article is distributed under the terms of the Creative Commons Attribution 4.0 International License (http://creativecomm ons.org/licenses/by/4.0/), which permits unrestricted use, distribution, and reproduction in any medium, provided you give appropriate credit to the original author(s) and the source, provide a link to the Creative Commons license, and indicate if changes were made.

\section{References}

Ahmad N, Berg D, Simons GR (2011) The integration of analytical hierarchy process and data envelopment analysis in a multicriteria decision-making problem. Int J Inf Technol Decis Mak 5(2):263-276

Chen MF, Zhang XY (2001) Fuzzy comprehensive evaluation method for evaluating water injection development in oilfields. FaultBlock Oil Gas Field 8(2):27-30

Dolan JG (1989) Medical decision making using the analytic hierarchy process: choice of initial antimicrobial therapy for acute pyelonephritis. Med Decis Mak 9:51

Gerbacia W, Hanaa AS (2001) Multi-criteria decision making in strategic reservoir planning using the analytic hierarchy process. SPE71413 Technical Conference and Exhibition, 30 September-3 October, New Orleans, Louisiana

Hou J, Zhang SK, Zhang YH, Wang RR, Luo FQ (2011) Prediction of microscopic remaining oil distribution using fuzzy comprehensive evaluation. Transp Porous Media 89(3):533-545
Liang P, Liu S (2016) Evaluation of water flooding development effect in low permeability oil field. Contemp Chem Ind 45(2):400-403

Ma J, Zhang W (2016) Evaluation of water flooding development effect by using water storage rate and water flooding index. Contemp Chem Ind 45:387-389

Miyamoto S (2000) Multisets and fuzzy multisets—soft computing and human-centered machines. Springer, Japan, pp 9-33

Saaty TL (1977) A scaling method for priorities in hierarchical structures. J Math Psychol 15:234-241

Sun N (2008) Comprehensive evaluation of water flooding effect in low permeability reservoirs. Spec Oil Gas Reserv 15(6):56-58

Tong XZ (1978) Discussion on statistical laws of natural water flooding and artificial water injection reservoirs. Petr Explor Dev 6:38-67

Torra V (2010) Hesitant fuzzy sets. Int J Intell Syst 25(6):529-539

Wen H, Sun N, Liu Y (2017) Index system evaluating water flooding development effect of oilfield at ultra-high water cut stage. J Pet Explor Prod Technol 7(1):111-123

You CM, Wang JC, Sun XJ, Lv XH, Song SM (2014) The application of multistage fuzzy comprehensive evaluation mathematics method for the analysis of determining the remaining oil in ultrahigh water-cut oilfield. Adv Mater Res 926-930:4429-4432

Zadeh LA (1965) Fuzzy sets. Inf Control 8(3):338-353

Zadeh LA (1974) The concept of a linguistic variable and its application to approximate reasoning-learning systems and intelligent robots. Springer, New York, pp 199-249

Zheng W, Tian Q (2009) The application of entropy method and AHP in weight determining. Comput Program Skills Maint 22:19-20

Zheng W, Jiang HQ, Chen MF, Zhang FB (2011) Fuzzy comprehensive evaluation for injection-production effectiveness in medium-high water cut stage. In: Asia-Pacific power and energy engineering conference. IEEE Computer Society, pp 1-4

Publisher's Note Springer Nature remains neutral with regard to jurisdictional claims in published maps and institutional affiliations. 